\title{
EFEITO DA ADUBAÇÃO POTÁSSICA E DA É POCA DE COLHEITA NA PRODUTIVIDADE DE CANOLA ${ }^{(1)}$
}

\author{
C. A. V. ROSSETTO ${ }^{(2)}$, J . NAKAGAWA ${ }^{(3)} \&$ C. A. ROSOLEM ${ }^{(3)}$
}

\begin{abstract}
RESUMO
O experimento foi desenvolvido na Fazenda Experimental São Manuel da Universidade Estadual Paulista, Campus de Botucatu, em Latossolo VermelhoAmarel o fase arenosa, no ano de 1996, com o objetivo de estudar o efeito da adubação potássica e da época de colheita na produtividade de canola (Brassica napus L. var. oleifera Metzg.). $O$ delineamento experimental foi o de blocos ao acaso com parcelas subdivididas, com quatro repetições. As parcelas constituíram-se de duas doses de potássio (0 e $40 \mathrm{~kg} \mathrm{ha}^{-1}$ de K), e as subparcelas, de sete épocas de coll heita, realizadas em intervalos semanais, no período de 112 a 154 dias após a semeadura. A adubação potássica não favoreceu o crescimento das plantas e a produtividade de sementes de canola, porém acarretou maior retenção das síliquas nas colheitas realizadas aos 147 e 154 dias da semeadura. A época de colheita não resultou em benefício consistente ao rendimento de sementes. $\mathbf{O}$ máximo de matéria seca da parte aérea das plantas foi atingido aos 112 dias da semeadura, e o das sementes, aos 126 dias, na presença da adubação potássica.
\end{abstract}

Termos de indexação: Brassica napus, maturação, potássio.

\section{SUMMARY: CANOLA SEED YIELD AS AFFECTED BY POTASSIUM FERTILIZATION AND HARVEST TIME}

A field experiment was carried out to study the effects of potassium fertilization and time of harvesting on canola seed yield. The soil was a Red-Yellow Latosol (Hapludox), and the experimental design was a subpl ot replicated four times in completely randomized blocks. Potassi um leve s ( 0 and $40 \mathrm{~kg} \mathrm{ha}^{-1}$ of $\mathrm{K}$ ) were applied in the plots, and the subplots consisted of 7 weekly harvests, starting 112 days after planting. Yield and yi el d components wereevaluated at each harvest. Although no positive effect of potassium fertilization on seed yield and growth parameters was evident, this fertilization caused higher retention of pods from the harvest at 147 and 154 days after planting. Time of harvesting did not affect seed yield. The maximum level of dry matter of the above ground part of the plants was obtained from the harvest at 112 days, and, of seeds, at 126 days, at high potassi um level.

Index terms: Brassica napus, maturation, potassium levels.

\footnotetext{
(1) Trabalho realizado dentro das atividades da bolsa de recém-doutor, concedida pelo CNPq ao primeiro autor, no Departamento de Agricultura e Melhoramento Vegetal da UNESP. Recebido para publicação em julho de 1997 e aprovado em janeiro de 1998.

(2) Professora Adjunta do Departamento de Fitotecnia, UFRRJ . CEP 23.851-970 Seropédica (RJ ).

(3) Professor Titular do Departamento de Agricultura e Melhoramento Vegetal, Faculdade de Ciências Agronômicas, UNESP. Caixa Postal 237, CEP 18.603-970 Botucatu (SP). Bolsista do CNPq.
} 


\section{INTRODUÇÃO}

A canola éuma variedade de colza (Brassica napus L. var. oleifera), desenvolvida por melhoristas canadenses, e que está sendo recomendada como cultura de inverno na região Centro-Sul do Brasil, para extração de óleo dos grãos (Martin \& Nogueira J unior, 1993). Porém, muitos fatores de manejo da cultura devem ser mais bem compreendidos para a implantação, condução e obtenção dos benefícios decorrentes de sua exploração.

A col heita é uma das mais importantes etapas do processo de produção, principalmente no que se refere ao método e ao momento em que deve ser executada. Os frutos (síliquas) não amadurecem uniformemente, resultando em perdas da parte inferior da inflorescência, enquanto os da parte superior ainda não se encontram maduros (Sims, 1979). Além disso, as col heitas realizadas em épocas inadequadas podem levar a consideráveis perdas em quantidade e qualidade de sementes, resultantes da deiscência rápida que a espécie apresenta, quando as síliquas atingem a maturidade fisiológica (Borba et al ., 1982).

Barni et al. (1984a,b,c) relataram que, na col heita antecipada, quando as sementes estão adquirindo a coloração marrom e, ou, preta, evitam-se as perdas pela deiscência das síliquas. Na colheita normal, realizada quando $90 \%$ das síliquas estão amareladas einiciando-se a deiscência natural das síliquas apicais, propicia-sea col heita mecanizada, porém podeocorrer redução dos rendimentos ocasionada pela deiscência das síliquas. No entanto, para Borba et al. (1982), a colheita anteci pada como método de redução de perdas não resulta em benefício consistente, assemel handose ao método da colheita normal, principalmente quando ocorrem ventos fortes e chuvas intensas durante a colheita. A colheita manual e a colheita enleirada manual, quando realizadas no início da maturação, com cerca de $30 \%$ de água e, ou, com a coloração marrom, diminuem as perdas da produtividade de sementes (Santos et al., 1988).

Outro aspecto de importância na produtividade de sementes de canola é o fornecimento adequado de nutrientes, dentre os quais o potássio, que é um elemento de destaque no aumento do peso das sementes e na resistência ao desenvolvimento de doença causada por Alternaria brassicae (Sharma \& Kolte, 1994). Além disso, as interações desse nutriente com onitrogênio e o boro podem afetar a produtividade e a qualidade das sementes (Daliparthy \& Barker, 1994). Todavia, May et al. (1994) não encontraram efeito favorável da adubação potássica na produtividade da canola.

Na soja, a importância do potássio está relacionada com a retenção das vagens nas plantas, redução da deiscência das vagens, resistência ao fungo Diaporthe phaseol orum (Mascarenhas et al., 1976) edimi nuição de vagens mal formadas (Mascarenhas et al., 1994). A adubação potássica também pode influir na composição química das sementes de soja, e plantas sob deficiência desse nutriente amadurecem antes, mesmo com sementes mal formadas (Rosolem et al., 1984). Em relação aos rendimentos de soja, Mascarenhas et al. (1994) observaram respostas favoráveis às fontes de potássio na produtividade apenas no experimento conduzido em Latossolo Vermelho-Amarelo com baixo teor de potássio, mas Rosolem et al. (1984) verificaram efeito favorável da adubação potássica na produtividade em Latossolo Vermelho-E scuro com teor médio de potássio.

O objetivo deste trabal ho foi estudar, em condições de campo, o efeito da adubação potássica e da época de col heita na produtividade da canola.

\section{MATERIAL E MÉTODOS}

O experimento foi desenvolvido em condições de campo, em Latossolo Vermel ho-Amarel ofase arenosa, série Mangueira Seca, de baixa fertilidade natural (Espindola et al., 1974), no município de São Manuel (SP), pertencenteà Fazenda Experimental São Manuel do Campus de Botucatu, da Universidade Estadual Paulista. As análises de terra, efetuadas de acordo com Raij \& Quaggio (1983), revelaram os seguintes val ores: $11 \mathrm{~g} \mathrm{~kg}^{-1}$ de matéria orgânica, $\mathrm{pH}\left(\mathrm{CaCl}_{2}\right)$ de 4,1, $34 \mathrm{mmol}_{\mathrm{c}} \mathrm{kg}^{-1}$ de $\mathrm{H}+\mathrm{Al}, 0,9 \mathrm{mmol}_{\mathrm{C}} \mathrm{kg}^{-1}$ de $\mathrm{K}^{+}$, 3,0 $\mathrm{mmol}_{\mathrm{C}} \mathrm{kg}^{-1}$ de $\mathrm{Ca}^{2+}, 1,0 \mathrm{mmol}_{\mathrm{C}} \mathrm{kg}^{-1}$ de $\mathrm{Mg}^{2+}$, $40 \mathrm{mmol}_{\mathrm{C}} \mathrm{kg}^{-1}$ de CTC e $6,0 \mathrm{mg} \mathrm{kg}^{-1}$ de $\mathrm{P}$ disponível.

O delineamento experimental utilizado foi o de bl ocos ao acaso com parcel as subdi vidi das, com quatro repetições. As parcelas (presença e ausência de potássio) foram constituídas por nove linhas, espaçadas de 0,20 m entre si, com comprimento de $28,0 \mathrm{~m}$, as quais foram divididas em sete subparcelas (épocas de col heita) de 4,0 m de comprimento. Foram consideradas, como área útil à col heita, as cincolinhas centrais de cada subparcela, desprezando-se $0,5 \mathrm{~m}$ de cada extremidade, compreendendo uma área de $3,0 \mathrm{~m}^{2}$.

A semeadura foi realizada manualmente, em 10 de abril de 1996, utilizando-se sementes do cultivar I ciola-41, cuja análise prel iminar, deacordocom Brasil (1992), revel ou os seguintes valores: $70 \mathrm{~g} \mathrm{~kg}^{-1}$ deágua, $89 \%$ de germinação e peso de mil sementes de 3,0 g. A densidade de semeadura foi de $4,5 \mathrm{~kg} \mathrm{ha}^{-1}$, com base no trabal ho de Barni et al. (1984a). Na adubação de semeadura, foram aplicados $44 \mathrm{~kg} \mathrm{ha}^{-1}$ de fósforo, na forma de superfosfatosimples; $20 \mathrm{~kg}$ ha-1 denitrogênio, na forma de sulfato de amônio, e $40 \mathrm{~kg}$ ha-1 de potássio, na forma de cloreto de potássio, nas parcelas que receberam esse nutriente.

Os tratos culturais constaram de capinas, com enxada, para o controle de plantas daninhas, e aplicações de fungicida (pó mol hável com $500 \mathrm{~g} \mathrm{~kg}^{-1}$ de iprodione), à dose de $1,5 \mathrm{~g} \mathrm{~L}-1$, após 12 dias da semeadura, ede inseticida ( $25 \mathrm{~g} \mathrm{~L}^{-1}$ dedeltamethrine), à dose de $300 \mathrm{~L}$ ha-1 de calda, aos 40 dias da semeadura. A adubação de cobertura foi realizada 30 dias após a semeadura, aplicando-se $50 \mathrm{~kg} \mathrm{ha-1}$ de nitrogênio na forma de sulfato de amônio. A irrigação foi realizada duas vezes por semana, nos primeiros 
40 dias, e, no restante do ciclo, uma vez por semana, utilizando-se o sistema por aspersão.

As épocas de col heita tiveram início 58 dias após o florescimento, quando foi observada a deiscência das síliquas que se apresentavam com a col oração pal ha, seguindo em intervalos de sete dias. Realizaram-se, manualmente, as col heitas aos 112 (01/08/96), 119 (08/ 08/96), 126 (15/08/96), 137 (22/08/96), 144 (29/08/96), 151 (5/9/96) e 158 (12/09/96) dias da semeadura. Em cada colheita, todas as plantas de cada subparcela foram cortadas rente ao solo, contadas e separadas em plantas com e sem síliquas (aquelas com até três síliquas por planta, com base em Barni et al., 1984a). Com base nesses dados, foram obtidos o número de plantas por $\mathrm{m}^{2}$ e a porcentagem de plantas com síliquas. As plantas com síliquas foram secas ao sol e, posteriormente, foram realizadas a trilha manual ea avaliação do grau de umidade e da produtividade de sementes (Brasil, 1992). Os dados de produtividade foram corrigidos para $90 \mathrm{~g} \mathrm{~kg}^{-1}$ de água.

Além disso, em cada col heita, foram analisadas amostras desíliquas, visando à determinação do grau de umidade inicial das sementes (Brasil, 1992), e amostras de 10 plantas contínuas, de uma das linhas de cada subparcela, visando à avaliação dos componentes de produção. Essas plantas, cortadas rente ao solo, foram separadas em parte vegetativa (parte aérea da haste principal e dos ramos primários, secundários eterciários) e parte reprodutiva (síliquas). Posteriormente, as síliquas sofreram trilha manual para a separação das sementes. A parte aérea das plantas foi avaliada quanto à altura da planta e ao número dos ramos (primários, secundários, terciários e total), e a parte reprodutiva foi avaliada quanto ao número e peso das síliquas e ao número e peso de sementes. Com esses dados, foram calculados o número de sementes por síliquas e o peso de mil sementes. Posteriormente, a parte aérea das plantas e as sementes foram col ocadas para secar em estufa a $60^{\circ} \mathrm{C}$, visando à determinação da matéria seca.

A análise estatística baseou-se em procedimentos encontrados em Gomes (1990). As variáveis expressas em porcentagem e em número foram transformadas, respectivamente, em arco seno $\sqrt{\mathrm{x}}$ e $\sqrt{\mathrm{x}}$. A comparação das médias foi efetuada pelo teste de Tukey, ao nível de 5\% de probabilidade.

\section{RESULTADOS E DISCUSSÃO}

Por ocasião do início das col heitas, 112 dias após a semeadura (DAS), verificou-se que as sementes estavam com pequeno desenvolvimento e $430 \mathrm{~g} \mathrm{~kg}^{-1}$ de água (Quadro 1); com o decorrer das col heitas, esse valor foi abaixando, atingindo $127 \mathrm{~g} \mathrm{~kg}^{-1}$, aos 154 DAS. Os graus de umidade das sementes foram semel hantes para os tratamentos com e sem adubação potássica.

O número total de plantas não diferiu entre os tratamentos, indicando uniformidade da população final das plantas. A quantidade de sementes $(4,5 \mathrm{~kg}$ ha1), utilizada na instalação do experimento, previa o estabel ecimento de uma população de 135 plantas por $\mathrm{m}^{2}$; no entanto, essa população reduziu-se para 52 plantas por $\mathrm{m}^{2}$, na média dos tratamentos com e sem adubação potássica (Quadro 1). Tal fato evidenciou que o elevado número de sementes não resultou no desenvolvimento de plantas, bem como a competição entre estas, associada a outros fatores do meio, deve ter contribuído para a redução na

Quadro 1. Grau de umidade das sementes no momento da colheita, número total de plantas por $\mathrm{m}^{2}$, porcentagem de plantas com síliquas, grau de umidade das sementes na trilha e produtividade de sementes de canola, considerando época de colheita e ausência $(S / K)$ ou presença $(C / K)$ da adubação potássica

\begin{tabular}{|c|c|c|c|c|c|}
\hline Tratamento & $\begin{array}{l}\text { Grau de umidade } \\
\text { na colheita }\end{array}$ & $\begin{array}{l}\text { Número total de } \\
\text { plantas }\end{array}$ & $\begin{array}{l}\text { Plantas com } \\
\text { síliquas }\end{array}$ & $\begin{array}{c}\text { Grau de umidade } \\
\text { na trilha }\end{array}$ & $\begin{array}{c}\text { Produtividade de } \\
\text { sementes }\end{array}$ \\
\hline Dias após a semeadura & $\mathrm{g} \mathrm{kg}^{-1}$ & plantas $\mathrm{m}^{-2}$ & $\%$ & $\mathrm{~g} \mathrm{~kg}^{-1}$ & $\mathrm{~kg} \mathrm{ha}^{-1}$ \\
\hline 112 & $430 a^{1}$ & $58,0 \mathrm{a}$ & $59,7 \mathrm{a}$ & $97 \mathrm{a}$ & $335 a$ \\
\hline 119 & $359 \mathrm{~b}$ & $58,0 \mathrm{a}$ & 49,0 a & $93 a$ & $340 \mathrm{a}$ \\
\hline 126 & $289 \mathrm{c}$ & $54,0 \mathrm{a}$ & $60,6 a$ & $97 a$ & $309 a$ \\
\hline 133 & $248 c$ & $51,0 a$ & 48,1 a & 92 a & $320 a$ \\
\hline 140 & $174 \mathrm{~d}$ & $55,0 \mathrm{a}$ & 55,1 a & $70 \mathrm{~b}$ & $315 a$ \\
\hline 147 & $148 d$ & $49,0 \mathrm{a}$ & $57,7 a$ & $78 \mathrm{~b}$ & $554 a$ \\
\hline 154 & $127 \mathrm{~d}$ & $42,0 \mathrm{a}$ & 65,7 a & $74 \mathrm{~b}$ & $421 \mathrm{a}$ \\
\hline Média S/K & $247 \mathrm{~A}$ & $50,0 \mathrm{~A}$ & $53,1 \mathrm{~A}$ & $85 \mathrm{~A}$ & $367 \mathrm{~A}$ \\
\hline Média $\mathrm{C} / \mathrm{K}$ & $260 \mathrm{~A}$ & $55,0 \mathrm{~A}$ & $60,0 \mathrm{~A}$ & $87 \mathrm{~A}$ & $374 \mathrm{~A}$ \\
\hline C.V. Parcela (\%) & 11,08 & 15,35 & 16,67 & 6,43 & 55,16 \\
\hline C.V. Subparcela (\%) & 11,64 & 2,21 & 0,35 & 5,82 & 23,33 \\
\hline
\end{tabular}

(1) Médias seguidas das mesmas letras (minúsculas para época de col heita e maiúsculas para adubação potássica) não diferem entre si significativamente ao nível de $5 \%$ de probabilidade, pelo teste de Tukey. 
população final, à semelhança do observado por Barni et al. (1984a, 1985).

A porcentagem de plantas com síliquas, por ocasião da col heita, não diferiu entre os tratamentos (Quadro 1). Além disso, observa-se que, em média, $40,0 \%$ das plantas deixaram de produzir síliquas nos tratamentos com adubação potássica, enquanto nos tratamentos sem adubação potássica, a porcentagem de plantas sem síliquas foi de 46,9\% (Quadro 1).

Por ocasião da trilha, os graus de umidade das sementes col hidas nas quatro primeiras épocas, até os 133 dias da semeadura, não diferiram entre si e foram superiores aos obtidos nas demais épocas, indicando maior grau de umidade para as sementes mais imaturas. Todavia, os graus de umidade das sementes foram semelhantes para os tratamentos com e sem adubação potássica (Quadro 1).

A produtividade de sementes foi semel hante para os tratamentos com esem adubação potássica, embora tenha sido constatada uma tendência de aumento na presença desse nutriente (Quadro 1). May et al. (1994) também não encontraram efeito favorável do potássio na produtividade de canola.

Em relação às épocas de col heita na produtividade de sementes (Quadro 1), observou-se que a colheita realizada 93 dias após o início do florescimento das plantas (147 DAS), quando as sementes apresentavamse com $148 \mathrm{~g} \mathrm{~kg}^{-1}$ de água, em média, resultou em mai or rendimento, porém a análise estatística não acusou diferença significativa em relação às demais épocas de col heita (Quadro 1).
Borba et al. (1982) também observaram que a época de col heita, como método de redução de perdas, não resultou em incremento do rendimento de sementes. No entanto, Santos \& Sattler (1990), empregando o método da col heita manual, encontraram rendimento de $1.600 \mathrm{~kg}$ ha-1 de sementes, aos 71 dias do pleno florescimento das plantas, quando as sementes apresentavam-se com $210 \mathrm{~g} \mathrm{~kg}^{-1}$ de água.

Além disso, com a col heita no início de setembro (147 DAS), é possível incluir-se a canola no sistema de sucessão de culturas, como a soja; considerando o ciclo, observa-se que esse cultivar poderia ser considerado como precoce, em vista dos critérios adotados por Bonetti \& Tragnago (1982). No quadro 1, observa-se, também, a tendência de diminuição da produtividade de sementes na última época de col heita (154 DAS), resultante da queda e deiscência rápida das síliquas, quando estas atingiram a maturidadefisiológica. Tais resultados concordam com as informações obtidas por Borba et al. (1982) eBarni et al. (1984a).

Neste experimento, a produtividade de sementes foi bem menor quea esperada, assim como a população de plantas e a porcentagem de plantas com síliquas (Quadro 1). As causas prováveis desse desempenho teriam sido os ventos fortes e as chuvas ocorridas durante as épocas de col heita mais tardias; fato que aconteceu em menor intensidadenas primeiras épocas (F igura 1). Resultados similares foram observados por Borba et al. (1982). Silva et al. (1983) constataram produtividade de 300 a $549 \mathrm{~kg} \mathrm{ha}^{-1}$, consideradas reduzidas, e que caracterizaram a canola como uma
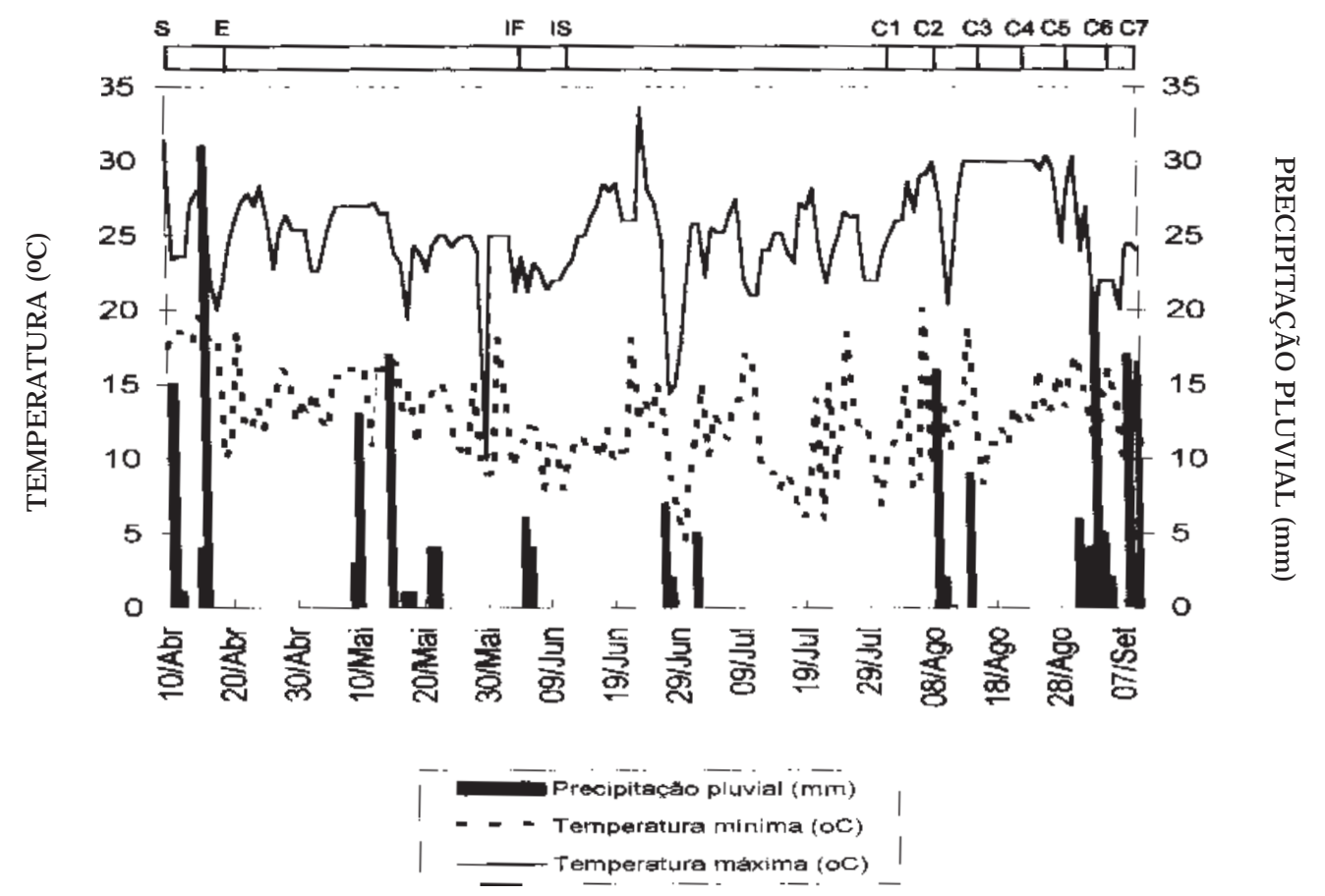

Figura 1. Dados diários de preci pitação pluvial e de temperaturas do ar máxima e mínima durante o período experimental do ano de 1996. E stádios de desenvolvimento das plantas: $\mathrm{S}=$ semeadura, $\mathrm{E}=$ emergência das plântulas, IF = início de florescimento, IS = início de formação de síliquas, C1 a C7 = colheitas. 
como uma espécie de alta sensibilidade às condições do meio no qual é cultivada, fato também verificado por Bonetti \& Vieira (1981).

A altura da planta e o número de ramos (primários, secundários, terciários e total), por planta, não apresentaram diferenças estatísticas entre os tratamentos (dados não apresentados), demonstrando que o crescimento das plantas ea formação dos ramos se haviam estabilizado por ocasião da primeira col heita, não tendo a adubação potássica favorecido o crescimento das plantas.

Analisando os demais componentes de produção (Quadro 2), pode-severificar quea adubação potássica acarretou aumento no número total de síliquas, por ter proporcionado maior número na haste principal e nos ramos primários, secundários e terciários, notadamente nas últimas col heitas (147 e 154 DAS).

É interessante ainda observar que o número de síliquas foi maior nas primeiras colheitas, tanto na haste principal como nos ramos, tendo sido este fato mais marcante quando na ausência de potássio, mostrando que as síliquas presentes nas primeiras colheitas não se mantiveram até as últimas. Nos tratamentos com potássio, entretanto, nota-se que o decréscimo do número de síliquas foi menor, indicando maior retenção das síliquas (Quadro 2), concor dando com os resultados obtidos para soja (Mascarenhas et al., 1994).

Em trigo, Beringer (1982) observou a presença de nível elevado e precoce do ácido abscísico nos grãos do tratamento sem adubação potássica. Considerando estar esse fitormônio relacionado com a abscisão dos frutos, pode-se inferir que o potássi o tenha contribuído efetivamente para a maior retenção de síliquas.
O maior acúmulo de matéria seca total da parte aérea das plantas foi atingido aos 112 DAS (Quadro 3), assim como o da haste principal e dos ramos (dados não apresentados); sendo esse período considerado crítico, pois envolve o florescimento, a frutificação ea maturação. Com o decorrer das colheitas, houve diminuição da matéria seca total recolhida (Quadro 3). Casarini et al. (1984) verificaram o acúmulo crescente de matéria seca da parte aérea das plantas atéa fase de pleno fl orescimento. Conte- Castro(1996) também verificou diminuição da matéria seca na fase de maturação e atribuiu tal fato à queda de folhas nessa fase do ciclo da cultura. Além disso, não houve diferença entre os tratamentos com e sem adubação potássica, confirmando não ter tal fertilizante favorecido o crescimento das plantas, como constatado pela altura das plantas.

O maior acúmulo de matéria seca total das síliquas foi observado aos 126 DAS, embora não tenha diferido estatisticamente do encontrado aos 112 DAS; após, com o decorrer das colheitas, houve diminuição da matéria seca total das síliquas (Quadro3). Em relação à adubação potássica, não foi observado efeito favorável desse nutriente, embora tenha sido encontrado aumento na presença deste, assim como para a porcentagem de plantas com síliquas (Quadro 1). No entanto, observou-se efeito favorável da adubação potássica na produção de matéria seca das sementes; assim, na presença desse fertilizante, observou-se que o maior acúmulo foi encontrado aos 126 DAS e, na ausência, aos 112 DAS (Quadro 3), como comprovado para o número total de síliquas (Quadro 2).

O número de sementes por síliqua e o peso de mil sementes não diferiram entre os épocas de colheita (Quadros 4 e 5). Em relação à adubação potássica,

Quadro 2. Número de síliquas da haste principal e dos ramos primários, secundários e terciários e número total de síliquas, por planta de canola, considerando época de colheita e ausência (S/K) ou presença (C/ K) da adubação potássica

\begin{tabular}{|c|c|c|c|c|c|c|c|c|}
\hline \multirow{2}{*}{ Tratamento } & \multicolumn{2}{|c|}{ Haste principal } & \multicolumn{2}{|c|}{ Ramos } & \multicolumn{2}{|c|}{ Ramos terciários } & \multicolumn{2}{|c|}{ Total } \\
\hline & $\mathbf{S} / \mathbf{K}$ & $\mathbf{C} / \mathbf{K}$ & Primários & Secundários & $\mathbf{S} / \mathbf{K}$ & $\mathbf{C} / \mathbf{K}$ & $\mathbf{S} / \mathbf{K}$ & $\mathbf{C} / \mathbf{K}$ \\
\hline Dias após a semeadura & & & & $\mathrm{n}^{\mathrm{o}}$ & & & & \\
\hline 112 & $47,3 \mathrm{Aa}^{1}$ & $36,9 \mathrm{Aab}$ & $54,5 \mathrm{a}$ & $33,2 a b$ & $42,2 \mathrm{Aa}$ & $34,0 \mathrm{Aab}$ & $223,7 \mathrm{Aa}$ & $175,6 \mathrm{Aa}$ \\
\hline 119 & $28,9 \mathrm{Ab}$ & $38,5 \mathrm{Aab}$ & $41,8 a b$ & $40,3 a$ & 5,5 Bbc & $34,9 \mathrm{Aa}$ & $100,5 \mathrm{Bb}$ & $171,7 \mathrm{Aab}$ \\
\hline 126 & $36,5 \mathrm{Aab}$ & 45,6 Aa & $52,2 \mathrm{a}$ & $39,5 a b$ & $22,1 \mathrm{Ab}$ & 25,3 Aab & $144,1 \mathrm{Ab}$ & 169,1 Aab \\
\hline 133 & $13,2 \mathrm{Bbc}$ & $27,0 \mathrm{Ab}$ & 24,2 bc & $21,0 \mathrm{bc}$ & $5,4 \mathrm{Bbc}$ & $22,4 \mathrm{Aab}$ & $48,4 \mathrm{Bbc}$ & $110,3 \mathrm{Ab}$ \\
\hline 140 & $12,9 \mathrm{Bbc}$ & $31,1 \mathrm{Ab}$ & 24,8 bc & 18,9 bc & 7,9 Abc & $16,6 \mathrm{Ab}$ & $51,3 \mathrm{Abc}$ & $104,9 \mathrm{Ab}$ \\
\hline 147 & $15,2 \mathrm{Bbc}$ & $30,7 \mathrm{Ab}$ & 25,6 bc & 22,2 bc & $7,2 \mathrm{Bbc}$ & $22,2 \mathrm{Aab}$ & $56,7 \mathrm{Bbc}$ & $114,6 \mathrm{Aab}$ \\
\hline 154 & $10,3 \mathrm{Bbc}$ & $27,3 \mathrm{Ab}$ & 24,4 bc & $17,5 \mathrm{c}$ & $2,8 \mathrm{BC}$ & $17,0 \mathrm{Aab}$ & $40,7 \mathrm{BC}$ & $100,8 \mathrm{Ab}$ \\
\hline $\begin{array}{l}\text { Média } S / K \\
\text { Média } C / K\end{array}$ & & & $\begin{array}{l}29,5 \mathrm{~B} \\
41,2 \mathrm{~A}\end{array}$ & $\begin{array}{l}25,3 \text { B } \\
35,4 \text { A }\end{array}$ & & & & \\
\hline C.V. Parcela (\%) & 14,25 & & 17,34 & 31,00 & 40,95 & & 18,56 & \\
\hline C.V. Subparcela (\%) & 1,59 & & 2,55 & 3,97 & 7,55 & & 1,29 & \\
\hline
\end{tabular}

\footnotetext{
${ }^{(1)}$ Médias seguidas das mesmas letras (minúsculas para época de colheita e maiúsculas para adubação potássica) não diferem entre si significativamente ao nível de $5 \%$ de probabilidade, pelo teste de Tukey.
} 
Quadro 3. Matéria seca da parte aérea das plantas (haste principal e ramos primários, secundários e terciários), das síliquas (sementes, valvas e replo) e das sementes, por planta de canola, considerando época de colheita e ausência (S/K) ou presença (C/K) da adubação potássica

\begin{tabular}{|c|c|c|c|c|}
\hline \multirow{2}{*}{ Tratamento } & \multirow{2}{*}{ Parte aérea } & \multirow{2}{*}{ Síliquas } & \multicolumn{2}{|c|}{ Sementes } \\
\hline & & & $\mathbf{S} / \mathbf{K}$ & $\mathrm{C} / \mathrm{K}$ \\
\hline Dias após a semeadura & 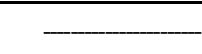 & -2 & & \\
\hline 112 & $17,62 a^{1}$ & $4,82 a b$ & $1,28 \mathrm{Aa}$ & $0,77 \mathrm{Babc}$ \\
\hline 119 & $14,56 \mathrm{ab}$ & $3,76 \mathrm{~b}$ & $0,73 \mathrm{Abc}$ & $0,87 \mathrm{Aab}$ \\
\hline 126 & $11,66 \mathrm{~b}$ & $6,43 a$ & $0,98 \mathrm{Aab}$ & $0,94 \mathrm{Aa}$ \\
\hline 133 & $12,18 b$ & $3,37 \mathrm{~b}$ & $0,24 \mathrm{Abcd}$ & $0,45 \mathrm{Abc}$ \\
\hline 140 & $10,58 \mathrm{~b}$ & $3,56 \mathrm{~b}$ & $0,23 \mathrm{Abcd}$ & $0,55 \mathrm{Abc}$ \\
\hline 147 & $12,01 \mathrm{~b}$ & $3,68 \mathrm{~b}$ & $0,24 \mathrm{Abcd}$ & $0,54 \mathrm{Abc}$ \\
\hline 154 & $10,71 \mathrm{~b}$ & $3,14 \mathrm{~b}$ & $0,23 \mathrm{Abcd}$ & $0,50 \mathrm{Abc}$ \\
\hline Média S/K & $13,27 \mathrm{~A}$ & $3,80 \mathrm{~A}$ & & \\
\hline Média $\mathrm{C} / \mathrm{K}$ & $12,36 \mathrm{~A}$ & $4,42 \mathrm{~A}$ & & \\
\hline C.V. Parcela (\%) & 22,04 & 33,83 & 39,48 & \\
\hline C.V. Subparcela(\%) & 36,71 & 20,45 & 28,06 & \\
\hline
\end{tabular}

(1) Médias seguidas das mesmas letras (minúsculas para época de col heita e maiúsculas para adubação potássica) não diferem entre si significativamente ao nível de $5 \%$ de probabilidade, pelo teste de Tukey.

Quadro 4. Número de sementes por síliqua da haste principal e dos ramos primários, secundários, terciários e total, por planta de canola, considerando época de colheita e ausência (S/K) ou presença (C/K) da adubação potássica

\begin{tabular}{|c|c|c|c|c|c|}
\hline Tratamento & Haste principal & Ramos primários & Ramos secundários & Ramos terciários & Total \\
\hline \multicolumn{6}{|l|}{ Dias após a semeadura } \\
\hline 112 & $17,5 a^{1}$ & $18,1 \mathrm{a}$ & $17,1 \mathrm{a}$ & 7,6 a & $15,9 a$ \\
\hline 119 & 16,8 a & 19,9 a & $16,1 \mathrm{a}$ & 3,6 a & $16,5 \mathrm{a}$ \\
\hline 126 & $22,0 \mathrm{a}$ & $18,6 \mathrm{a}$ & $16,6 \mathrm{a}$ & $5,3 a$ & 17,7 a \\
\hline 133 & $14,3 \mathrm{a}$ & $12,1 \mathrm{a}$ & 9,9 a & $3,6 \mathrm{a}$ & $10,9 a$ \\
\hline 140 & $17,9 a$ & $15,6 \mathrm{a}$ & $11,0 \mathrm{a}$ & $5,7 \mathrm{a}$ & $13,2 \mathrm{a}$ \\
\hline 147 & $16,0 \mathrm{a}$ & $12,0 \mathrm{a}$ & $17,5 a$ & 9,1 a & $12,9 a$ \\
\hline 154 & $14,4 \mathrm{a}$ & 13,6 a & $8,7 \mathrm{a}$ & 7,1 a & 11,7 a \\
\hline Média S/K & $18,1 \mathrm{~A}$ & $16,1 \mathrm{~A}$ & $14,7 \mathrm{~A}$ & $8,1 \mathrm{~A}$ & $14,1 \mathrm{~A}$ \\
\hline Média $\mathrm{C} / \mathrm{K}$ & $15,9 \mathrm{~A}$ & $15,3 \mathrm{~A}$ & $13,0 \mathrm{~A}$ & $3,8 \mathrm{~B}$ & $13,1 \mathrm{~A}$ \\
\hline C.V. Parcela (\%) & 26,36 & 22,25 & 36,33 & 65,90 & 20,64 \\
\hline C.V. Subparcela (\%) & 4,30 & 4,76 & 7,03 & 16,15 & 4,20 \\
\hline
\end{tabular}

(1) Médias seguidas das mesmas letras (minúsculas para época de col heita e maiúsculas para adubação potássica) não diferem entre si significativamente ao nível de $5 \%$ de probabilidade, pelo teste de Tukey.

observou-se que, na presença desse fertilizante, houve diminuição do número de sementes por síliqua dos ramos terciários (de 8,1 para 3,8 sementes por síliqua) eaumento do peso de mil sementes (de 1,03 para 2,53 g por mil sementes) dessas silíquas; nos demais ramos e na haste principal, não houve efeito da adubação potássica. Sharma \& Kolte (1994) também verificaram efeito favorável da adubação potássica no peso de mil sementes.
Pelos quadros 4 e 5, pode-se verificar que, tanto para número de sementes por síliqua como para peso de 1.000 sementes, foram obtidos os maiores valores para os da haste principal e os menores para os dos ramos terciários, mostrando a seqüência de acúmulo de matéria seca nas sementes com o desenvol vimento dos frutos e das sementes. Além disso, o maior valor de peso de mil sementes da haste principal foi encontrado na col heita realizada aos 147 DAS, embora 
Quadro 5. Peso de mil sementes das síliquas da haste princi pal e dos ramos primários, secundários, terciários e total, por planta de canola, considerando época de colheita e ausência (S/K) ou presença (C/K) da adubação potássica

\begin{tabular}{cccccc}
\hline Tratamento & Haste principal & Ramos primários & Ramos secundários & Ramos terciários & Total \\
\hline Dias após a semeadura & & & & & \\
\cline { 2 - 5 } 112 & $4,00 \mathrm{a}^{1}$ & $3,75 \mathrm{a}$ & $3,06 \mathrm{a}$ & $2,25 \mathrm{a}$ & $3,48 \mathrm{a}$ \\
119 & $3,71 \mathrm{a}$ & $3,91 \mathrm{a}$ & $3,53 \mathrm{a}$ & $1,14 \mathrm{a}$ & $3,67 \mathrm{a}$ \\
126 & $3,84 \mathrm{a}$ & $3,64 \mathrm{a}$ & $3,13 \mathrm{a}$ & $1,58 \mathrm{a}$ & $3,59 \mathrm{a}$ \\
133 & $3,51 \mathrm{a}$ & $3,31 \mathrm{a}$ & $2,44 \mathrm{a}$ & $0,59 \mathrm{a}$ & $3,08 \mathrm{a}$ \\
140 & $3,75 \mathrm{a}$ & $3,38 \mathrm{a}$ & $2,79 \mathrm{a}$ & $2,57 \mathrm{a}$ & $3,65 \mathrm{a}$ \\
147 & $4,22 \mathrm{a}$ & $3,56 \mathrm{a}$ & $3,12 \mathrm{a}$ & $2,62 \mathrm{a}$ & $3,48 \mathrm{a}$ \\
154 & $3,42 \mathrm{a}$ & $3,60 \mathrm{a}$ & $2,96 \mathrm{a}$ & $1,03 \mathrm{~B}$ & $3,48 \mathrm{~A}$ \\
Média S/K & $3,72 \mathrm{~A}$ & $3,29 \mathrm{~A}$ & $3,01 \mathrm{~A}$ & $2,53 \mathrm{~A}$ & $3,51 \mathrm{~A}$ \\
Média C/K & $3,84 \mathrm{~A}$ & $3,91 \mathrm{~A}$ & $3,00 \mathrm{~A}$ & 78,62 & 29,73 \\
C.V. Parcela (\%) & 29,30 & 32,70 & 47,67 & 74,82 & 21,05 \\
C.V. Subparcela (\%) & 21,12 & 25,44 & 23,21 & \\
\hline
\end{tabular}

(1) Médias seguidas das mesmas letras (minúsculas para época de col heita e maiúsculas para adubação potássica) não diferem entre si significativamente ao nível de $5 \%$ de probabilidade, pelo teste de Tukey.

a análise estatística não tenha acusado diferença significativa em relação às demais col heitas, coincidindo com a época de colheita que tendeu a proporcionar a maior produtividade de sementes (Quadro 1).

\section{CONCLUSÕES}

1. A adubação potássica não favoreceu o crescimento das plantas e a produtividade de sementes de canola, porém acarretou maior retenção das síliquas nas colheitas realizadas aos 147 e 154 dias da semeadura.

2. A época de col heita, como método de redução de perdas, não resultou em benefício consistente ao rendimento de sementes.

3. A maior produção dematéria seca da parteaérea das plantas de canola foi obtida aos 112 dias da semeadura, e das sementes, aos 126, na presença da adubação potássica.

\section{AGRADE CIMENTO}

Ao Prof. Dr. Adelson Paulo de Araújo, do Departamento deSolos da Universidade Federal Rural do Rio de J aneiro, pelas sugestões apresentadas.

\section{LITERATURA CITADA}

BARNI, N.A.; HILGERT, E.R.; BAPTISTA, J.C. \& GUTTERES, J.P. Desempenho de cultivares de colza (Brassica napus $L$. var. ol eifera Metzg.) em resposta a épocas de semeadura e locais. Agron. Sulriog., 20:11-44, 1984a.
BARNI, N.A.;WESTPHALEN, S.L.; BERGAMASCHI, H.; GOMES, J.E.S. \& GONÇALVES, J.C. Efeito do espaçamento e densidade de semeadura sobre o desempenho agronômico da colza (Brassica napus L. var. oleifera Metzg.) a épocas de semeadura na depressão central do Estado do Rio Grande do Sul. Agron. Sulriog., 20:63-74, 1984b.

BARNI, N.A.; BERGAMASCHI, H.;WESTPHALEN, S.L.; GOMES, J .E.S. \& GONÇALVES, J .C. Resposta da colza (Brassica napus L. var. ol eifera M etzg.) a épocas de semeadura na depressão central do Estado do Rio Grande do Sul. Agron. Sulriog., 20:75$100,1984 c$.

BARNI, N.A.; HILGERT, E.R.; ZANOTELLI, V.; VARGAS, J.N.R.; TEDESCO, A.; BOHN, D.; GOMES, J.E.S. \& GONÇALVES, J.C. Introdução e avaliação de cultivares de colza (Brassica napus L. var. oleifera Metzg.) no Estado do Rio Grande do Sul. Agron. Sulriog., 21:21-54, 1985.

BERINGER, H. O potássio na produção das culturas. In: Yamada, T. ed. Potássiona agricultura Brasileira. Piracicaba, Instituto International de Potassa, 1982. p.163-175.

BONETTI, L.P. \& VIEIRA, R.E. Avaliação de cultivares de colza em diferentes épocas de semeadura. Trigo Soja, PortoAlegre, 55:16-9, 1981.

BONETTI, L.P. \& TRAGNAGO, J.L. Avaliação de cultivares introduzidas de colza. In: REUNIÃO ANUAL DE PROGRAMAÇÃO DE PESQUISA E DE ASSISTÊNCIA TÉ CNICA DA COLZA, PortoAlegre, 1982. Anais. PortoAlegre, FECOTRIGO, 1982. p.1-7.

BORBA, C.S.; BARNI, N.A.; J AMARDO, A.; GOMES, J.E.S.; GONÇALVES, J.C. \& SARTORI, G. É poca de colheita, rendimento de grãos e qualidade das sementes de colza (Brassica napus L. var. oleifera Metzg.). Agron. Sulriog., 18:3958, 1982.

BRASI L. Ministério da Agricultura e Reforma Agrária. Regras para análise desementes. Brasília, SNPA/DNDV/CLAV, 1992. 365p. 
CASARINI, M.A.G.S.; HAAG, H.P.; SFREDO, G.J . \& MINAMI, K. Absorção, concentração e exportação de nutrientes por duas linhagens de colza (Brassica napus) em função da idade. Imacronutrientes. Anais da ESALQ, 61:37-75, 1984.

CONTE-CASTRO, A.M. Efeito do espaçamento e densidade de semeadura na marcha de absorção de nutrientes e na produtividade de canola. Botucatu, UNESP, 1996. 115p. (Tese de Mestrado).

DALIPARTHY, J \& \& BARKER, A.V. Potassium fractions with other nutrients in crops: a review focusing on the tropics. J. Plant Nut., 17:1859-1886, 1994.

ESPINDOLA, C.R.; TOSIN. W.A.C. \& PACCOLA, A.A. Levantamento pedológico da Fazenda Experimental São Manuel. In: CONGRESSO BRASILEIRO DE CIÊNCIA DO SOLO, 14., Santa Maria, 1974. Anais. Santa Maria, Sociedade Brasileira de Ciência do Solo, 1974. p. 650-654.

GOMES, F.P. Curso de estatística experimental. 3.ed. Piracicaba, Escola Superior deAgricultura "L uiz de Queiroz", 1990. 468p.

MARTIN, N.B. \& NOGUEIRA J UNIOR, S. Canola: uma nova alternativa agrícola de inverno para o centro-sul brasileiro. Inf. Econ., 23:9-24, 1993.

MASCARENHAS, H.A.A.; MIRANDA, M.A.C.; BATAGLIA, O.C.; TISSELI FILHO, O.; BRAGA, N.R. \& SOAVE, J. Efeito da adubação potássica sobre o ataque da soja pelo Diaporthe phaseol orum. Summa Phytopathol., 2: 2304, 1976.

MASCARENHAS, H.A.A.; TANAKA, R.T.; GALLO, P.B. \& PEREIRA, J.C.V.N.A. Eficiência das fontes de potássio para a soja. O Agronômico, 46:1-3, 1994.
MAY, W.E.; HUME, D.J \& \& HALE, B.A. Effects of agronomic practices on free fatty acid levels in the oil of Ontario-grown spring canola. Can. J. Plant Sci., 74:267-274, 1994.

RAIJ, B. van \& QUAGGIO, J .A. Métodos de análise de solo para fins defertilidade. Campinas, InstitutoAgronômico, 1983. 31p.

ROSOLEM, C.A.; NAKAGAWA, J. \& BERBEL, R. A nutrição potássica na produção e qualidade das sementes de soja. In: SEMINÁRIO NACIONAL DE PESQUISA DE SOJ A, 3. Campinas, 1984. Anais. 1984. p.921-929.

SANTOS, H.P.; PEREIRA, L.R.; LHAMBY, J.C.B. \& NEDEL, J.L. Manejo de col heita no rendimento de grãos de Colza de 1980 a 1983. Pesq. Agrop. Bras., 23:1247-1253, 1988.

SANTOS, H.P. \& SATTLER, A. Efeito do manejo de col heita sobre o rendimento de grãos de Colza. Pesq. Agrop. Bras., 25:15851592, 1990.

SHARMA, S.R. \& KOLTE, S.J . Effect of soil applied NPK fertilizers on severity of black spot disease (Alternaria brassicae) and yield of oilssed rape. Plant Soil, 167:313- 320, 1994.

SILVA, M.I .; MARCHEZAN, E. \& CALLEGARO, I.C. Avaliação do comportamento agronômico de cultivares de colza introduzidas. In: REUNIÃO ANUAL DE PROGRAMAÇÃO DE PESQUISA E DE ASSISTÊNCIA TÉCNICA DA CULTURA DA COLZA, Passo Fundo, 1983. Anais. Passo Fundo, Centro de Ciências Rurais/UFSM, 1983. p.9-13.

SIMS, R.E.H. Problems of harvesting oilseed rape. Big Farm Manage, 2:44-57, 1979. 